\title{
Aspect Regarding the Design of Active Strategies for Venture Capital Financing - the Flexible Adjustment for Romania as a Frontier Capital Market
}

\author{
Gabriela Prelipcean \\ University "Stefan cel Mare of Suceava, Romania \\ Mircea Boscoianu \\ Transilvania University of Brasov, Romania
}

\section{Abstract}

Industry 4.0 revolution find a real interest of entrepreneurs but in the case of frontier and emerging markets it is difficult to find a reliable source of long-term financing. The decoupling of the technological evolution from the evolution of the access to financing capacities must be analysed from different point of view (financial, legislative, socio- technical). In Romania, as a frontier market there are only few alternative investment solutions capable to respond to the long-term financing demand of performant projects. The main interest is to understand the strategies for adaptation of venture capital fund (VCF) at real conditions. Venture capital funds (VCF) represents a particular form of private equity investments, scale down and more focused on innovative start-up (or even expansions on technology or markets) projects (the typical value is 10 mil Euro). This form of investments is a personalized response to the general problem related to the actors that do not have tangible assets for collaterals and / or cannot demonstrate the ability to make a profit. In the case of VCF, as a vehicle oriented on innovation and technology, the business plan represents the main element for project portfolio selection in the context of matching the interests of investors with the interests of financed firm's managers. This contribution is especially important for the case of frontier and emerging markets characterized by additional restrictions (access to strategies, liquidity problems, and agency costs beyond a simple monitoring). For Romania, it is essential to adapt VCF investors' objectives to all phases (selection, evaluation, contract signing and restructuring, progress monitoring, stimulating value-added and, especially, closing the VCF cycle) to real conditions and considering the performance indicators balancing with the value creation mechanisms specific of industry 4.0.

Keywords: venture capital fund VCF, innovative start-up projects, business plan, active selection

JEL classification: G24, M13, O16

\section{Introduction to the issue of venture capital funds VCF - the situation in Romania}

In Romania, although the macroeconomic characteristics are favorable, there are only few alternative solutions that are capable of responding to the long- term financing demand of the start-up performing projects. The actual interest is to understand the strategies for harmonizing funding capabilities with the real projects 
proposed by entrepreneurs and the fructification of the strategic solutions through flexible adaptation of investment vehicles like venture capital funds (VCF) at real market conditions.

The specific conditions refer in fact to the inefficiencies specific to the market category in which Romania belongs, namely frontier market, but with real perspectives to skip to another status, namely emerging market. Progress has been made in terms of legislative issues, but the Romanian alternative fund industry does not harmonize well enough either with investors (especially retail) or with entrepreneurs seeking long-term financing (Boscoianu et al., 2015). In order to remedy this situation, not only alternative investment fund managers, but all stakeholders, authorities, managers of companies interested in financing and investors should participate.

Although in Romania direct investment is still preferred, the recent emergence of alternative investment funds (AIFs) opens new flexible perspectives that provide easy and scalable access to long-term project financing, starting from the principles of modularity, scalability and competitive selection. In emerging markets, delegating decision-making to investment managers (Boscoianu et al., 2018) becomes essential because it optimizes the investment cycle through flexibility and efficiency and provides adequate response to market restrictions (liquidity, critical mass, access barriers, additional scaling and monitoring costs).

To reveal the actual situation of the financing venture capital into emerging markets, it can start from the general framework of financial buyer solutions (Bruton et al., 2009; Bottazzi and Hellmann, 2008; Alhorr et al., 2008). Private Equity (PE) / Private Equity Funds (PEF) are long-term financing solutions for over 100 million Euros of performing business/ projects (the current global trend is growing by an order of magnitude) and include a wide range of activities and mechanisms such as: acquisition of mature companies demonstrating leveraged buyout (LBO) capacities; minority equity investments offered to firms for expansion/ restructuring (growth capital) have created firms in early development or expansion (pure venture capital investments). The financial buyers are different from the strategic buyers based on their ability of acquiring a more leveraged capital structure with more favorable debt financing elements and efficient exit strategies. Moreover, based on the premises offered by the alternative investment funds for the emerging markets, the chances for a safe diversification and the establishment of a better management strategic orientation are still there.

The venture capital funds (VCF) represent a particular form of scaled down PEFs (in the case of those funds that are one unit less than PEF and a typical value of 10 million Euro) and are more focused on the innovative start-up (or even the expansions on technology or markets) projects. The VCF investments represent a personalized response to the general issue related to those actors that do not own tangible assets for collaterals and/or are not able to prove their initial ability to generate profit (Amit et al., 1998). On the other hand, within the emerging markets, the LBO elements are also viewed as the portfolio's consolidating elements.

\section{The VCF's technical and organizational particularities in the emerging markets}

Although private equity or venture capital solutions are well known in the investment landscape, there are few references and concrete examples to Romania. In order to describe the solutions and effective trading strategies of these instruments, we will detail specific organizational and technical particularities in some emerging markets. 
First of all, let present the VCF transactions participants in emerging markets. The management of VCF selects the targeted firm, negotiate the acquisition price, secure debt financing, makes strategic and financial decisions and decide the strategic timing of investment (the characteristics of exit). In emerging markets, the investors are limited partner's type. They sign the invest contracts for as long 8-10 years being limited by the exit strategies (IPO/ strategic sale). The role of the management of the targeted firms is critical in the context of alignment of interests of management with interests of VCF.

In order to understand how to improve the viability of VCFs, it is important to make reference to the main characteristics of the transactions in the emerging markets:

0 it is mandatory to configure those critical securitisation elements (debt and equity) that are required by the institutional investors (Bekaert and Harvey, 2003);

- there are high debt levels set in place starting from the intention of increasing the return on equity for PEF/ VCF investors;

- regarding the exit strategy, the capability to resold a VCF- portfolio company after 5-8 years through an IPO (initial public offering) depends on the efficiency of markets and it is still preferred the private transaction solution (Cumming, 2008);

- the companies in VCF portfolios target an IRR (internal rate of return) above $25 \%$ in the context of a higher leverage, an inconsistent ability to pay dividends and another market's inefficiencies;

- the VCFs have some effects on companies and markets such as: pressures on performance, focus on anti-takeover strategies, the possibility of a further readjustment of the capital structure (the leverage via additional debt to reduce the overall cost of capital and improve the returns), the streamlining of the mergers and acquisitions.

One can notice the importance of the introduction of a set of solutions that will adjust the VCF investments to the actual situation in Romania such as:

- the growth of the efficiency of the partnerships based on the investment and management cultures;

- taking part in some large transactions based on the flexibility of the partnerships (the so called "club transactions");

- the leveraged recapitalizations of VCF portfolios via debt transactions.

Another question is related to the process of selection of the target companies for the VCF transactions. In Romania, the capital market is still underdeveloped and even if there are good companies, the investment opportunities are lost in the wake of market inefficiencies (Boscoianu et al., 2013; Prelipcean et al., 2014). The process of selection of the target companies for the VCF portfolios differs significantly from other investment funds. The key selection element is the VCF business plan that comprises differentiating elements in regards to the market, the product, the IPR rights, the management team, the operation history, the financial projects, the necessary funds and the exist opportunities (Anson, 2008). The plan needs to be a coherent and a consistent one (Kaplan and Stromberg, 2009). It needs to be based on the business strategy connected with the targeted niche. It also needs to emphasize the necessary resources and the risks that can be encountered on the way, the ability of the management team up in order to design an efficient and a viable set of actions that will accomplish the target performances. The plan also needs to be realistic and offer both the funding stages and the supplementary adjustment amounts. The financial objectives need to comprise both the profit indicators and the exit conditions (IPO or the strategic transaction). 
One needs to highlight the fact that the VCF within the emerging markets could also comprise the LBOs with those companies that are able to generate cash flow (to pay debt interest, the main payments and dividends). In emerging markets, the investors are more focussed on returns, on cutting down the actual investment period as well as on the efficiency of the exit strategies. The inclusion of certain PE/LBO types of elements would generate the premises for portfolio stabilizations.

The critical characteristics of the VCF companies within the emerging markets are related to:

- the quality of management (in the case of a high leveraged company, the rigorousness and the quality of decisions are essential) and assets (the assets are oriented towards the growth in cash flow and sales);

- ensuring a stable and a robust cash-flow (the management's ability to ensure cost savings and operational initiatives);

- taking steps towards improving the capital structure in the context of a higher leverage, an efficient structured debt and a smaller equity investment that is able to induce a greater potential return;

- a good control of the capital expenditure.

VCF managers manage fundraising processes, portfolios selection, structuring investments in their portfolio companies, investment monitoring, value added service offerings, and design the exit scheme at the end of the investment cycle. This involves a set of highly complex activities (selection decisions, investment timing, and management of large investment blocks, additional capital injections, or restructuring/closure solutions, alternative exit solutions through IPO). The main advantage of VCF is the possibility of staging (Gompers, 1995), and mathematically this can be represented by a Call option with leverage implications (option value increases with volatility). In this case, the issue of compensation for risk comes from the financed beneficiary, a novel aspect that could be used in the case of Romania.

In the case of VCF, as a vehicle oriented on innovation and technology the business plan represents is the main element for project portfolio selection in the context of matching the interests of investors with the interests of financed firms' managers. The active involvement of the investment manager in managerial assistance and technical advice, including the setting of operational objectives (detailed and correlated with business plans), progress monitoring and operational management, offers the advantage of reducing the information asymmetry specific to mediums with high uncertainties and low liquidity. For Romania, it is essential to adjust the VCF investors objective in all stages (selection, evaluation, agreements and re-structuring, the progress' monitoring, the encouragement of getting the added value and, most of all, bringing VCF to a closure) of real life situations by taking into account the connection between the performance indicators and the typical Industry 4.0 value design mechanisms.

This contribution is especially important in the case of frontier and emerging markets characterized by additional restrictions (the access to strategies, the liquidity problems, agency costs beyond a simple monitoring).

\section{The Innovative solutions for adjusting VCF to the Romanian capital market}

Although VCF contracts have a well-defined place in medium and long-term financing, a careful consideration of the adaptation of VCF funding solutions is needed in current context in Romania. 
VCF finances innovative projects with high associated risk and low liquidity, and in the case of emerging markets it faces additional barriers to investment (liquidity, political instability, information asymmetry, fund transfer restrictions, taxes), exacerbation of uncertainty issues and predisposition to turbulent. VCF in emerging markets are in fact niche strategies and the active involvement of the investment manager in monitoring the company's progress and operational management becomes essential. In this type of managerial assistance and business technical advice, VCF participation must contain the management of detailed operational objectives, related to business plans.

The attractiveness of VCF investments in emerging markets involves balancing performance items beyond the risk-return binom so that even sometimes significant differences in investment timing are considered. VCF performance cannot be compared to benchmarking as in the case of alternative investment funds and there is no question of a risk benchmarking, the portfolio being built on the fruition of market opportunities.

VCF funding solutions offer unique benefits both to the company that can access impossible financing through classic investments and to the financier who benefits from the opportunity of a staged investment that can be represented by a Call with Leverage implications. Since the value of the option increases with the volatility of the project / portfolio of financing projects, it results in creating a preference for long-term investment involving a higher risk. In addition, within the VC financing partnership, a more prudent, risk-clearing attitude is created at the same time by the VCF fund manager. This risk adjustment mechanism is of utmost importance for the VCF funding contracts in emerging markets.

Within VCF in emerging countries, the key selection element, which also supports the management contract, is the business plan. It is essential in this case to harmonize the interests of VCF investors with those of companies from portfolio (especially financial projections, associated risks, impact on the VCF portfolio, and the effectiveness of exit strategies). In addition to highlighting the necessary resources and risks along the way, the business plan must reflect the ability of the management team to achieve the proposed performance. The plan should be realistic by providing the sequence of funding and additional adjustment investments, and the financial targets should contain both profitability indicators and public exit conditions through IPO.

The typical lifecycle of the VCF funding in emergent markets follows the GompersLerner curve (Gompers and Lerner, 2001), and at these stages there are a number of particularities such as:

a) attracting initial capital from underwriting external investors is a non-transparent process of "club transactions" and the duration may differ significantly (3-12 months);

b) the analysis of the companies' business plans basically takes place in parallel with the action itself;

c) the initial investments are in a closed system and without showing the stage profit at VCF level and the duration differs significantly depending on the type of projects (about 1.5 - 5 years), it is desired to include LBO elements as stabilization machines;

d) the investments' active management within the VCF portfolio (including further capital investments) stand for a flexible element that functions together with the leveraged recapitalizations of VCF portfolios via debt transactions and do not exclude their involvement in large transactions;

e) monitoring, management, and technical support are key elements in generating a constant profit that will be able to sustain the VCF strategy; 
f) finalising the VCF investment cycle can be taken into account in advance based on early redemptions due to the fact that the IPO strategies target more performing markets.

The complexity of adapting VCF funding to the emerging market context emphasizes the importance of governmental support both in creating new institutional and market infrastructures and in developing the investment culture specific to the current context in Romania.

Regarding the VCF financing mechanisms, in the case of Romania, there is a comparative advantage compared to the classical solutions and an added efficiency resulting from the inherent reduction of the moral hazard problems presented above. Through a better selection of projects, focusing on personalized contracts results in a good adaptation to specific target environments, characterized by information asymmetry and high uncertainty in which management of the problem of adverse selection can often be confronted with hidden actions leading to moral hazard.

The typical structure and classic VCF models indicate a long-term investment horizon that is not well connected to the requirements of emerging market investors. Thus, an initial investment phase of 1 to 3 years and a maturity stage in the 3-7 years implies the search for better adapted solutions. In addition, the closure of the Gompers-Lerner cycle (Gompers and Lerner, 2001; 2006) may create some surprises in the sense of a larger weight of liquidations or possible failed IPOs. In these circumstances, it is expected that the processes of alignment of alternative investorto-business interests will be specified in detail through performance objectives wellanchored by the specific sector.

For Romania, the harmonization of the objectives of VCF investors on all phases (selection, evaluation, contracting and structuring, monitoring progress, stimulating value-adding and, in particular, closing the VCF cycle) should start from understanding how to get performance indicators and creating collaborative and natural stabilization mechanisms. Alternative investment culture is another vector of integration and can be sustained through government-university partnerships. Scientific research in the field of attention can also contribute to the success of these investment vehicles.

\section{The use of real options in the VCF transactions - dealing with high uncertainties and turmoil}

VCF performance analysis should start from the idea that some of the portfolio companies do not deliver the proposed returns. Analysis of success probabilities by Bayesian processes and the continuation of investment processes by capitalizing new opportunities on the basis of updated beliefs (Bergemann and Hege, 1998) and new liquidity injections could also contribute to the stabilization of VCF portfolios.

In order to understand how to obtain stable and balanced performance, it is necessary to adapt the real option analysis ROA as a robust tool in dealing with investment uncertainty (Adner and Levinthal, 2004; Adner, 2007; Coff and Laverty, 2001) to the typical VCF financing mechanisms. In the literature (Trigeorgis, 1996) exist different types of real options: option to defer, grow, stage, scale, abandon, switch.

The management of real options focuses on the adequate implementation (from the selection of the projects, the decisions to continue the investments and the exit). The classic mechanism of the investment decisions is represented by the expending of resources with opportunity cost under uncertainty and irreversibility (Dixit et al., 1994). The use of real options in VCF starts from stating the advantage of 
understanding the multi- stage investments (Herath and Park, 2002) based on the building and managing of different real options (making use of those options that add in value and giving up the ones that do not add in value).

The financial option, defined as the right (but not the obligation) to take an action in the future (Amram and Kulatilaka, 1999; Kogut and Kulatilaka, 2001) provides protection against the unwanted price fluctuations. They characterized by the asymmetry that exists between the limited downside and an unlimited upside. On the other hand, the real options were defined (Trigeorgis, 1996) as contingent investments that secure future decision rights by offering both continuation/expansion opportunities (growth options allow subsequent investments leveraging the project) as well as defer or abandon (exit options). The sequential approach allows the inclusion of the updated information regarding the project's dynamics and allows the investment process to be more flexible (through learning and discovering).

The principle of investment timing starts from the observation of the combination of uncertainty and irreversibility and suggests the importance of introducing a wait or defer type $D$ option that represents the cost of waiting until the uncertainty is solved and the growth type $G$ (invest immediately to target the opportunity).

It is worth noting that in this case there is the possibility of NPV-D $<0$ even in the case of a feasible project from the classical perspective (NPV>0), but also investments that create value synergies through follow-on options, where a non-feasible project (NPV $<0)$ can become interesting, because NPV + G> 0. It should be noted that the influence factors of the financial call value (underlying asset, the exercise, the uncertainty, the risk-free rate, the maturity) changes for real options due to the fact that the exercise is not known and fixed (post divergence in valuation). In addition, there are costs that are associated in order to keep options open in the context that ambiguity is related to the maturity. Moreover, the transactions with real options could be influenced by adverse selection and information asymmetries.

In order to provide a typical VCF transaction application, we propose a timing model of investments with future expectations inspired by the Grenadier and Weiss (1997) model of current and future technology. It highlights the strategic potential of timing of investments starting from the assumption that sequential investments offer a source of vital of flexibility in environments with higher levels of uncertainty.

The formulation of decisions should start from the distinction between two types of options, capable of providing flexible responses to changes in markets, defer D option (wait/ delay and stage investments - benefits of waiting new information) and growth $G$ option (invest immediately or early investment - ability to expand in the future). Immediate investment may lead to missed participation in new market opportunities in the next round, while waiting strategy is penalized by an opportunity cost. This equation highlights the short-term or timing expectations of the market (ex-date dividend) and long-term developments. It is especially important to understand the relative G/D and G/D conflicts.

There is a two-generation model of opportunities that distinguishes between $G$ and D options, with opposite effects on the attitude of investment VCF. Timing and the momentum of emerging a future opportunity, VC2 is associated with uncertainty in comparative values and the frequency of change.

Let us consider two generations, a current opportunity ( $\mathrm{VCl}$ project) and a future opportunity (VC2 project) and two decisions related to the adoption of the current/ future opportunity. One needs to estimate the significance of the relative G/D value by starting from the value of the future opportunity, uncertainty in the current/ future values, the arrival time of the future opportunity. One will start from identifying the underlying source of uncertainty. The deferral option value is expressed by the 
opportunity cost of irreversibly investing in $\mathrm{VCl}$ project (uncertain value today). In the case of the growth option $G$, the aim is to maximize the potential value of VC2 project. The uncertainty of $\mathrm{VC} 1$ and $\mathrm{VC} 2$ could/ could not be related. In regards to the option values, higher uncertainty of $\mathrm{VC} 2$ lowers the $\mathrm{D}$ value of $\mathrm{VC} 1$ while increasing the $\mathrm{G}$ value of VC2. If VC2 represents only an incremental advance over $\mathrm{VC}$ 1, the changes in the value of $\mathrm{VC} 2$ have a small impact on the $\mathrm{VC} 1$ value.

One notices the existence of several mechanisms in generating values based on those two types of options. The way they are used depends on the actual situation. The $D$ value is determined by the opportunity cost of investing in VCl and suggests the adjustment of the decision according to the process of arrival of the new information. There is a trade-off between first mover advantage and the possible arrival of alternative future projects. On the other hand, the $G$ value depends on the preference for the investment in future projects by starting from the trust in solving the incertitude. After identifying the new investment method, the information changes the corresponding uncertainty level and, as a result, the VCF manager either makes use of the option (full investment) or stops the investment. The importance of the expected arrival time of VC2 originates from the protection mechanism of the initial investment given the fact that the monitoring costs diminish the $G$ value.

The real option analysis (ROA) is based on two essential elements such as the ability of the VCF managers of reacting naturally to the changing market conditions and the ability to react to the risk change. The main issues of the real option analysis (ROA) refer to the actual aspects regarding the implementation, the organizational aspects of the managing options, a profound understanding of those mechanisms of generating value based on real options as well as the quantitative estimate of the reason for maintaining open options.

The future research should consider aspects related to the timing of investments, a thorough research on the understanding of the value creation and the appropriate mechanisms working within real options in the context of VCF transactions, the introduction of the issue of valuing the abandonment options, the use of performance or risk measures to test ROA. Moreover, combining several theories such as the agency theory (the understanding of the usage limits), ranges (commitment vs flex for building performance) can be taken into account.

\section{Conclusion}

The VCF issue in Romania was barely analysed in the specialised literature. The present approach is unique due to the fact that it is meant to be a multi-dimensional analysis in itself based on the market's practical assumptions. Firstly, it tackles some aspects that were borrowed from the PEF/LBO as well as some hedge fund trading strategies that help introduce flexible solutions for the adjustment to the difficult conditions of the emerging markets. Secondly, some flexible staging mechanisms are emphasized based on a Call option that has an impact on the connection existing between the leverage and the compensation for risk.

VCF in emerging markets refer to a set of complex activities that start with the setting up of the initial structure, the set of decisions of the target companies, the investment timing and finishing with a large set of flexibilities (based on extra capital investments, restructuring/closing solutions, club transactions partnerships, leveraged recapitalizations of VCF portfolios via debt transactions, innovative exist solutions based on the IPO).

Regarding the strategies for adapting venture capital financing at the actual context, in Romania the support of the government (based on the Triple Helix partnerships in establishing/refining the specific investment culture and the 
upgrade/design of a new investment infrastructure) is one of an utmost importance (Prelipcean and Boscoianu, 2014).

The improvement of the performance based on the reduction of the moral hazard issues is done through the projects' transparent and competitive selection, a proper design of the contracts (based on finding a common ground of the interests through the performance objectives that are specific to a particular field), as well as a fluid personalization that adjusts to the investment stages that characterize the emergent markets (the duration of the investment, the IPO mechanisms).

As far as Romania is concerned, the clear statement of the VCF investors' objectives during all the stages (selection, evaluation, trading and structuring, the progress' monitoring, sustaining the added value and especially the closing of the VCF cycle) needs to emerge from the performance indicators and the typical Industry 4.0 value design mechanisms.

\section{References}

1. Adner, R., Levinthal, D. (2004), "What is not a real option: considering boundaries for the application of real options to business strategy", Academy of Management Review, Vol. 29, No. 1.

2. Adner, R. (2007), "Real options and resources reallocation process", in Rever, J., Tong, T. (Eds.), Real Options Theory, Advances in Strategic management, Vol. 24, Emerald Group Publishing Limited, Bingley, pp. 363-372.

3. Amram, M., Kulatilaka, N. (1999), Real options: managing strategic investment in an uncertain world, Harward Business School, Boston, MA.

4. Alhorr, H. S., Moore, C., Payne, T. (2008), "The Impact of Economic Integration on Crossborder Venture Capital Investments: Evidence from the European Union", Entrepreneurship Theory and Practice, Vol. 32, No. 5, pp. 897-917.

5. Amit, R., Brander, J., Zott, C. (1998), "Why Do Venture Capital Firms Exist? Theory and Canadian Evidence", Journal of Business Venturing, Vol. 13, No. 6, pp. 441-446.

6. Anson, M. J. P. (2008), The handbook of alternative assets, 3rd edition, Hoboken, John Wiley \& Sons.

7. Bekaert, G., Harvey, C. (2003), "Research in Emerging Markets Finance: Looking to the future", Emerging Markets Review, Vol. 3, No. 4, pp. 429-448.

8. Bergemann, D., Hege, U. (1998), "Venture capital financing, moral hazard, and learning", Journal of Banking and Finance, Vol. 22, No. 6-8, pp. 703-735.

9. Boscoianu, M., Prelipcean, G., Lupan, M. (2018), "Innovation enterprise as a vehicle for sustainable development - A general framework for the design of typical strategies based on enterprise systems engineering, dynamic capabilities, and option thinking", Journal of Cleaner Production, Vol. 172, pp. 3498-3507.

10. Boscoianu M., Prelipcean, G., Calefariu, E., Lupan, M. (2015), "Innovative Instruments for SME Financing in Romania - a New Proposal with Interesting Implications on Markets and Institutions", Procedia Economics and Finance, Vol. 32, p. 240-255.

11. Boscoianu, M., Prelipcean, G., Lupan, M. (2013), "Aspects regarding the effectiveness of innovative solutions for early stage SMEs financing in emerging markets", Management Marketing, Vol. 9, No. 2.

12. Bottazzi, L., Hellmann, T. (2008), "Who Are the Active Investors? Evidence from Venture Capital", Journal of Financial Economics, Vol. 89, No. 3, pp. 488-512.

13. Bruton, G. D., Chahine, S., Filatotchev, I. (2009), "Founders, Private Equity Investors, and Underpricing in Entrepreneurial IPOs", Entrepreneurship Theory and Practice, Vol. 33, No. 4, pp. 909-928.

14. Coff, R. W., Laverty, K. J. (2001), "Real options in knowledge assets", Business Horizons, Vol. 44, No. 6, pp. 73-80.

15. Cumming, D. (2008), "Contracts and Exits in Venture Capital Finance", Review of Financial Studies, Vol. 21, No. 5, pp. 1947-1982. 
16. Dixit, A. K., Dixit, R. K., Pyndyck, R. (1994), Investment under uncertainty, Princeton University Press.

17. Gompers, P. (1995), "Optimal investing, monitoring and the staging of venture capital", Journal of Finance, Vol. 50, No. 5, pp. 1461-1489.

18. Gompers, P., Lerner, J. (2001), "The Venture Capital Revolution", Journal of Economic Perspectives, Vol. 15, No. 2, pp. 145-168.

19. Gompers, P., Lerner, J. (2006), The Venture Capital Cycle, MIT Press.

20. Grenadier, W. (1997), "Investment in technological innovations; an option pricing approach", Journal of Financial Economics, Vol. 44, No. 3, pp. 397-416.

21. Herath, H. S. B., Park, C. S. (2002), "Multi-stage capital investment opportunities as compounded real options", The Engineering Economist, Vol. 47, No. 1, pp. 1-27.

22. Kaplan, S., Stromberg, P. (2009), "Should Investors Bet on the Jockey or the Horse? Evidence from the Evolution of Firms from Early Business Plans to Public Companies", Journal of Finance, Vol. 64, No. 1, pp. 75-115.

23. Kogut, B., Kulatilaka, N. (2001), "Capabilities as real options", Organization Science, Vol. 12, No. 6, pp. 744-758.

24. Prelipcean, G., Boscoianu, M., Lupan, M., Nastase, C. (2014), "Innovative Financing Solutions Based on Venture Capital and Private Equity to Support the Development of Entrepreneurship in Romania", Transformation in Business and Economics, Vol 13, No. 3C, pp. 331-347.

25. Prelipcean, G., Boscoianu, M. (2014), "A hybrid framework for SME financing based on the mix between governmental support and the use of a specialized investment fund in the actual context of a slow recovery after crises and turbulences", Procedia Economics and Finance, pp. 738-745.

26. Trigeorgis, L. (1996), Real options: managerial flexibility and strategy in resource allocation, MIT Press, Cambridge, MA.

\section{About the authors}

Gabriela Prelipcean is professor and PhD coordinator at the University Stefan cel Mare of Suceava. She holds a PhD in Management from the Academy of Economic Studies of Bucharest, a NEC Fellowships, financed by the New Europe College (NEC), Institute for Advanced Study, Bucharest, Romania and a postdoctoral Fulbright Scholarship in Economic Sciences at Elizabethtown College, Pennsylvania. She teaches several courses and she have a wide experience as researchers, on the topics of Investments, SMEs Financing, Venture Capital Fund, Economics of Disasters, Risk Management. The author can be contacted at gprelipcean@yahoo.com.

Mircea Boscoianu Professor Ph.D., is Ph.D. coordinator at Transilvania University of Brasov, Romania. Areas of competence: quantitative modelling, extreme risk events, financial crisis. Author and co-author of more than 7 books, over 80 papers published in journals or presented at scientific events, director or member in various research projects. He is member of the international and national associations. The author can be contacted at boscoianu.mircea@yahoo.com. 